\title{
LÍQUENS DA RESERVA BIOLÓGICA DO ALTO DA SERRA DE PARANAPIACABA (1)
}

\author{
Wilson Roberto Pereira (2) \\ Marcelo Pinto Marcelli (3)
}

\begin{abstract}
RESUMO - Corn o objetivo principal de levantamento florístico foi efetuado estudo de material depositado no herbário do Instituto de Botânica de São Paulo mais coletas dos autores no ano de 1988. Foram encontradas ao todo 63 espécies, sendo que a maior parte do material antigo não foi recoletado e a amostragem atual revela uma flora heliófila composta principalmente por Parmeliaceae. Lobariaceae presentes nas coletas antigas não puderam ser encontradas, sendo notada também a ausência de líquens fruticosos como Usnea e Ramalina. A alteração da mata por poluição do ar proveniente de Cubatão aliada às condições de excessiva umidade e sombra podem ser os fatores responsáveis pela pobreza da flora liquênica encontrada.
\end{abstract}

Palavras chaves: líquens, flora, São Paulo, mata pluvial.

\begin{abstract}
The biological reserve of the Serra de Paranapiacaba is part of the Serra do Mar at Santo André city, São Paulo state, Brazil $\left(23^{\circ} 47^{\prime}\right.$ S, $46^{\circ} 19^{\prime} \mathrm{W}, 800 \mathrm{~m}$ above sea level). It is covered with a tropical rain forest and is the most rainy place of Brazil. It stands near ( $16 \mathrm{~km})$ of Cubatão city (at sea level) from were receives a great deal of air pollutants. The principal aim of this work is verify the old and recent lichen floras of the reserve. Altogether 63 species were found. The most (16) of the 25 species held at the SP herbarium (Instituto de Botânica de São Paulo) could not be collected in 1988 and nowadays $60 \%$ of the lichens are Parmelia s.l. species. No Stictaceae or corticolous fruticose species, which are present at the herbarium. could be recollected in 1988. Air pollution, too high umidity and shade can together be the responsible for the flora poorness.
\end{abstract}

Key words: lichens, flora, São Paulo. rain forest.

(1) Trabalho executado dentro do Programa Linhas de Ação em Botânica do $\mathrm{CNPq}$ - Mata Atlàntica.

(2) Estagiário da Seção de Micologia e Liquenologia do Instituto de Botânica de Sẫu Paulo.

(3) Pedidos de separatas para Rua Guaxupé, 949 - Vila Formosa - CEP 03416 - São Paulo - SP. 


\section{Introdução}

A Reserva Biológica do Alto da Serra de Paranapiacaba localiza-se a $23^{\circ} 47^{\prime}$ de latitude Sul, $46^{\circ} 19^{\prime}$ de longitude Oeste (Mattos Filho, 1930), a 40 $\mathrm{km}$ da Praça da Se (centro) da cidade de São Paulo a $16 \mathrm{~km} \mathrm{NE}$ do centro de Cubatão, no município de Santo André.

A região possui uma altitude média de $800 \mathrm{~m}$ e ocupa uma área de 336 ha com relevo muito acidentado e declividade de $75 \%$, sendo coberta por vegetação do tipo "floresta tropical úmida de encosta", com solo do tipo "intergrade" litossolo fase substrato granito-gnaisse e apresenta as normais de precipitação de 3381mm anuais (Mattos Filho, 1930).

Embora a reserva seja antiga e famosa por suas belezas naturais, não existem trabalhos sobre a flora liquênica local.

O principal objetivo deste trabalho é o levantamento da flora liquênica do interior da reserva acompanhado de uma tentativa de comparação entre as flora atual e antiga.

\section{Metodologia}

Durante um ano (1988) foram efetuadas excursões de coleta com a finalidade de cobrir a maior área possível da reserva.

Indivíduos das espécies encontradas foram numerados, secos ao ar e, após identificados, depositados no herbário liquenológico da Seção de Micologia e Liquenologia do Instituto de Botânica (SP).

\section{Resultados e Discussões}

O levantamento de herbário revelou apenas 40 espécimens coletados desde o final do século passado até 1987 , sendo que a grande maioria deles são pedaços pequenos e muitas vezes estéreis de identificação difícil ou impossível.

As espécies constantes do herbário são as seguintes (entre parêntesis segue o número de $\mathrm{SP}$ ):

Baeomyces carneus Flk. (100876)

Cladia aggregata (Sw.)Nyl. (17761, 100749, 100751,100829)

Cladina confusa (R.Sant.) Follm. \& Ahti $(17237,100131)$

Cladonia ceratophylla (Sw.) Sprengl. $(2539,5892)$

Cladonia crispatula (Nyl.) Ahti (100140)

Cladonia didyma (Fée) Vainio(17792)

Cladonia pityrophylla $\mathrm{Nyl}(100830)$

Cladonia soiida Vainio (5917)

Cladonia sp.(5894, 17290, 17760, 100095, 100096, 100101, 100102, 100105)

Dictyonema glabratum (Spreng.) Hawksw., como Cora pavonia Fr. (17285,

22782, 100385)

Herpothallon sanguineum (Sw.) Tobler (100112) 
Líquens da Reserva Biológica...

Parmotrema cetratum (Ach.) Hale, como Parmelia cetrata Ach (100856)

Parmotrema mellissii (Dodge) Hale, como Parmelia mellissii Dodge (100853)

Parmotrema sp. (17739)

Pseudocyphellaria chlatrata (De Not.) Malme, como Sticta clathrata D.Nots. (34056)

Psorama sp. (17283)

Sphaerophorous australis Lour. (5921)

Stereocaulon proximum Nyl. $(5859,34057)$

Sticta damaecornis Ach. $(22780,22785)$

Sticta sinuosa Pers. (5919)

Sticta weigelii (Ach.) Vainio (5920)

Sticta sp. (17747)

Usnea baileyi Strth. (22784)

Usnea goniodes Strth. (22783)

As 47 espécies encontradas no levantamento de campo foram as seguintes:

Bulbothrix isidiza (Nyl.) Hale

Cladonia didyma (Fée) Fr.

Cladonia sp.

Dictyonema glabratum (Spreng.) Hawksw.

Dictyonema sericeum (Sw.) Berk.

Dimerella sp.

Dirinaria picta (Sw.) Clem. \& Shear

Dirinaria applanata (Fée) Awasthi

Graphis sp.

Herpothallon sanguineum Tobler

Herpothallom sp.

Heterodermia cf obscurata (Nyl.) Trev.

Heterodermia cf japonica (Sato)

Hypotrachyna bahiana (Nyl.) Hale

Hypotrachyna dentella (Hale \& Kurok.) Hale

Hypotrachyna cf dentella (Hale \& Kurok.) Hale

Hypotrachyna costaricencis (Nyl.) Hale

Hypotrachyna endochlora (Leighton) Hale

Hypotrachyna imbricatula (Zahlb.) Hale

Parmelina antillensis (Nyl.) Hale

Parmelina horrescens (Taylor) Hale

Parmelina schindleri Hale

Parmelina subfatiscens (Kurok.) Hale

Parmelina cf subfatiscens (Kurok.) Hale

Parmelina sp.

Parmotrema mellissii (Dodge) Hale

Parmotrema michauxianum (Zahlb.) Hale 
Parmotrema cf peralbidum (Hale) Hale

Parmotrema praesorediosum ( $\mathrm{Nyl}$.) Hale

Parmotrema reticulatum (Taylor) Hale

Parmotrema sancti-angeli (Lynge) Hale

Parrnotrema tinctorum (Despr.) Hale

Pertusaria sp.

Physcia albicans (Pers.) Nyl.

Physcia sorediosa (Vainio) Lynge

Pseudoparmelia cf alabamensis (Hale \& McCollough) Hale

Pseudoparmelia caroliniana (Nyl.) Hale

Pseudoparmelia crozalsiana (Bouly de Lesdain) Hale

Pseudoparmelia sphaerospora ( $\mathrm{Nyl}$.) Hale

Pseudoparmelia texana (Tuck.) Hale

Pseudoparmelia sp.

Phaeographis sp.

Punctelia rudecta (Ach.) Krog

Punctelia sp.

Sarcographa sp.

Thelotrema sp.

Usnea sp.

Foram encontradas ao todo (em coletas e herbário) 63 espécies, sendo que 16 das 25 espécies de herbário não foram recoletadas.

A maior parte das espécies encontradas em campo são de líquens folhosos com algas verdes, geralmente tidos como heliófilos, e foram encontradas apenas na beira de trilhas e clareiras, principalmente nos locais mais elevados. $\mathrm{O}$ interior da mata é praticamente desprovido de líquens, mesmo de espécies epífilas ou de Lobariaceae e Collemataceae, cuja ausência total causou estranheza, ainda mais que 4 espécies de Lobariaceae estão presentes nas antigas coletas.

A família Parmeliaceae sozinha aparece com 28 espécies (60\% do total), todos pertencentes ao antigo gênero Parmelia s.l., e Parmelina schindleri Hale é citada pela primeira vez para o estado de São Paulo.

Líquens tipicamente fruticosos como Ramalina e Usnea são estranha e totalmente ausentes (apenas um pequeno espécimen muito pequeno e estéril de Usnea foi encontrado).

Espécies crostosas ainda não foram trabalhadas a nível específico, mas também apareceram em número bastante inferior ao esperado pela comparação com o observado em outros trechos da Mata Atlântica não distantes da reserva.

Hoene (1925) descrevia a região como portadora de exuberantes paisagens, fauna e flora, citando exemplos destes entre as observações dos diversos ecossistemas. Ele reconhecia a importância de preservar o local em seu estado natural para garantir que estudos biológicos futuros encontrassem ali resgates históricos em condições mais originais possíveis. No entanto, desde sua época havia evidências das alterações no meio ambiente devido à atividade antrópica.

A região do Alto da Serra devido à sua geografia, é constantemente cer- 
cada por nevoeiros e nuvens orográficas que promovem muita umidade e alto índice pluviométrico anual.

Uma cobertura vegetal primária manteria os fatores hidro-climatológicos, como por exemplo a retenção de água no solo, em equilíbrio. No entanto, a poluição aérea provocada pela ação das indústrias de Cubatão, a retirada da camada de floresta original por desmatamentos, queimadas, deslizamentos, erosividade e erodibilidade, fragilizam a proteção das escarpas da Serra do Mar (Ab'Saber, 1987).

Essa fragilização pode ter atingido e alterado a flora liquênica original da região de duas maneiras:

Diretamente, os poluentes atmosféricos atuam sobre o metabolismo prejudicando o crescimento e alterando o desenvolvimento (Gilbert, 1973), como en. muitos indivíduos coletados, que apresentaram tamanho reduzido, esterilidade, descoloração e perda de vigor.

Indiretamente, a poluição, desmatamentos, deslizamentos e erosões, sujeitam os líquens tanto à falta de substrato (devido à morte ou retirada deste), quanto a alterações microclimáticas (pela alteração da estrutura da mata), expondo-os a condições desfavoráveis (Marcelli, 1987).

Por outro lado existem fatores mais naturais que poderiam explicar ou concorrer para a pobreza observada na flora liquênica.

Grande parte da mata da região da reserva é muito alta e consequentemente escura. Assim, a maioria dos líquens é encontrada apenas em galhos e troncos mais altos ou na beira de clareiras e trilhas. Esse fato não apenas reduz o número de habitats disponíveis como causa problema na amostragem das espécies.

O líquen, sendo composto por alga e fungo num relacionamento mutualístico, necessita ser "stressado" alternadamente, ou seja, exposto a dessecação e umedecimento para que seus componentes não tenham condições ideais para se desenvolverem isoladamente (Farrar, 1976; Pearson, 1970).

Assim, devido às suas condições hidroclimatológicas (indicada como uma das regiões de maior pluviosidade do país por Funari et al. 1986) a reserva pode não representar um local propício ao desenvolvimento dos líquens, pois não oferece os períodos necessários de dessecação.

A comparação da flora encontrada com a de outra região de Mata Atlântica que se apresente mais aberta e/ou com menos umidade seria uma maneira de avaliar em suas devidas proporções as influências de macro e microclima e das alterações ambientais na área estudada.

\section{Referências Bibliográficas}

AB 'SABER, A. N. 1987. Síntese dos conhecimentos. In: Anais do Simpósio sobre ecossistemas da costa sul e sudeste brasileira. V.2, p. 74-116.

FARRAR. J. F. 1976. The Lichen as an Ecosystem: Observation and Experiment. In: Lichenology: Progress and Problems, p. 385-406. eds. Brown. D. H.: Hawksworth. D. L. \& Bailey, R. H.. Academic Press, Londres. 
FUNARI, F. L.; STRUFFALDI-DEVUONO, Y. \& SALUM, S. T. 1986. Balanço hídrico de duas áreas de Mata Atlântica: Reserva Biológica de Paranapiacaba e Parque Estadual da Ilha do Cardoso (Estado de São Paulo). In: Anais do VI Congresso da Sociedade Botânica de São Paulo, p. 95-101.

GILBERT, O. L. 1973. Lichens and Air Pollution. In: The Lichens, p. 443-472. Eds. Ahmadjian. V. \& Hale Jr., M. E.. Academic Press. Nova Iorque.

HOENE, F. C. 1925. A Estação do Alto da Serra. Álbum da Seç̧ão de Botânica do Museu Paulista e suas dependências, $215 \mathrm{p}$.

MARCELLI, M. P. 1987. Ecologia dos Líquens dos manguezais da Região S-SE do Brasil, com Especial Atenção ao de Itanhaém (SP). Tese de doutoramento apresentada ao Departamento de Botânica do Instituto de Biociências da Universidade de São Paulo. $656 \mathrm{p}$.

MATTOS FILHO, B. 1930 A Estação Biológica do Alto da Serra sob o prisma meteorológico. Archivos do Instituto de Biologia, 3: 109-127.

PEARSON, L. C. 1970. Varying Environmental Factors in Order to Grow Intact Lichens Under Laboratory Conditions. Am. J. Bot., 57 (6) : 659-664. 